\title{
USO DA ESPECTROGRAFIA DE RAIO X NA DETERMINAÇÃO DO CÁLCIO E DO POTÁSSIO EM SOLOS *
}

\author{
J.L.I. DEMATTÊ $* *$ \\ N. HOLOWAYCHUCK
}

RESUMO

Foi estudado por espectrografia de raio $\mathrm{X}$ a distribuição do $\mathrm{Ca}$ e $\mathrm{K}$ na fração areia e no solo total em oito pedons representativos de uma topossequência de solos da região de São Pedro no Estado de São Paulo.

As principais conclusões foram as seguintes:

- Com exceção dos Pedons 1 e 3 os teores de $\mathrm{K}$ e Ca são muito baixos. Os elevados teores de $\mathrm{K}$ encontrados nos Pedons 1 e 3 indicam que os materiais das superfícies I e III são menos intemperizados e portanto de origem mais recente.

- A fração areia dos solos estudados, com exceção dos Pedons 1 e 3 , possue baixissimos valores de $\mathrm{K}$ e $\mathrm{Ca}$, consequentemente de minerais contendo tais elementos.

- Com exceção do Pedon 3 os solos não possuem reserva mineral na fração areia.

- De todos os solos estudados os Pedons 6, 7 e 8, localizados nas superfícies mais antigas, são os mais intemperizados.

\section{INTRODUÇÃO}

A utilização da espectografia de raio $\mathrm{X}$, em genese de solos, tem sido muito difundida nos últimos anos devido as característicás de rapidez na determinação das análises e na precisão dos resultados. Especificamente ela é utilizada para as análises elementares, sendo o Ti, Zr, $\mathrm{Fe}, \mathrm{Ca}, \mathrm{K}$ e Mn os elementos mais pesquisados. As determinações do Ti e Zr são conduzidas com o objetivo de pesquisar a homogeneidade de perfis de solos (Brewer, 1964; Khan, 1959; Chapman e Horn, 1968, Beavers, 1960; Alexander et alii, 1962; Handy e Rosouer, 1959; Foss and

* Entregue para publcação em 19-1-1977.

** Departameento de Solos e Geologia, E.S.A. "Luiz de Queiroz", Piracicaba, SP.

*** Agronomy Department, The Ohio State University. 
Beavers, 1968; Demattê, 1975), e os demais elementos juntamente com os dois primeiros são utilizados em estudos de ganhos e perdas (Beavers et alii, 1963; Khangarot, 1969; Smeck et alii, 1968; Dress, 1970).

Por outro lado a pesquisa destes elementos pode ser conduzida visando outros objetivos tais como: verificação da intensidade do intemperismo; obtenção de dados que poderão auxiliar na caracterização de superfícies fisiográficas; estudo da potencialidade de solos.

No presente trabalho procurou-se estudar o comportamento do $\mathrm{Ca}$ e do $\mathrm{K}$ em oito perfis de solos da região de São Pedro, Estado de São Paulo com os seguintes objetivos em mente:

a) Obtenção de dados que possam ser úteis na caracterização de materiais superficiais das superfícies fisiográficas estudadas;

b) Obtenção de informações a respeito da distribuição destes dois elementos com a profundidade como um possível indicador do intemperismo; solos.

c) Obtenção de informações a respeito do estado potencial dos

\section{MATERIAL E MÉTODOS}

Para o presente estudo foram utilizados oito pedons localizados na região de São Pedro, em uma topossequência indo do Rio Piracicaba na Depressão Periférica até o rio Jacaré-Pupira no Planalto Ocidental (Fig. 1). O Quadro 1 apresenta a relação solo e superfície assim como a sua classificação.

Quadro 1. Solos estudados; sua classificação, classe textural e relação com as superfícies fisiográfica (Demattê, 1975)

\begin{tabular}{|c|c|c|c|c|c|}
\hline & Posição & Pedon & $\begin{array}{l}\text { Superfície } \\
\text { fisiogra- } \\
\text { fica }\end{array}$ & Classificação do solo & $\begin{array}{c}\text { Classe } \\
\text { textural }\end{array}$ \\
\hline \multirow{4}{*}{$\begin{array}{c}\text { Depressão } \\
" \\
" \\
"\end{array}$} & io Periférica & 1 & I & Oxic Paleustult & \multirow{2}{*}{$\begin{array}{c}\text { barro fino } \\
" \|\end{array}$} \\
\hline & $"$ & 2 & II & Typic Haplustox & \\
\hline & . & 3 & III & Ustoxic Dystropept & \\
\hline & . & 4 e 5 & IV & Ustoxic Quartzipsamment & \multirow{4}{*}{$\begin{array}{c}\text { areia } \\
\text { argila } \\
\text { barro fino } \\
\text { argila }\end{array}$} \\
\hline \multirow{3}{*}{$\begin{array}{c}\text { Planalto } \\
" \\
"\end{array}$} & Ocidental & 6 & VI & Typic Acrustox & \\
\hline & $"$ & 7 & $\mathrm{~V}$ & Typic Acrustox & \\
\hline & $"$ & 8 & $\mathrm{r}$ & Typic Acrustox & \\
\hline
\end{tabular}


Análise por Fluorescência de raio $\mathrm{X}$

O cálcio e o potássio do solo e da fração areia foram determinados por fluorescência de raio $X$. A fração areia $(2-0,05 \mathrm{~mm})$ foi separada por análise convencional, por peneira, após a dispersão do solo. $\mathrm{O}$ solo total foi utilizado sem nenhum prévio tratamento. Três repetições foram preparadas de acordo com a técnica descrita por Rutledge (1969). Ácido bórico (30\% por peso) foi usado como agente diluente. Foi utilizado um aparelho Norelco com as seguintes condições:

Elemento analisado: Ca; tubo: Cr; cristal analisador: LiF; potencial: $40 \mathrm{kv}$; corrente: $20 \mathrm{ma}$; colimador: grosso; contador: proporcional a 1600 volts, PHA: 4,0 volts na linha base e 14,0 volts na janela; função: contagem fixada em 100.000; pico: $113,39^{\circ} 2 \theta, \mathrm{K} \alpha 1$ e $\mathrm{K} \alpha 2$; caminho: vácuo com pressão menor que $200 \mu$.

Elemento analisado: $\mathrm{K}$; tubo: $\mathrm{Cr}$; cristal analisador: PET; potencial $40 \mathrm{kv}$; corrente: 20 ma; colimador: grosso; contador: proporcional a 1600 volts; PHA: 5,0 volts na linha base e 14,0 volts na janela; função: contagem fixa em 100.000 ; pico $51,02^{\circ} 2 \theta ; \mathrm{K} \alpha 1$; e $\mathrm{K} \alpha 2$; caminho vácuo.

\section{RESULTADOS E DISCUSSÃO}

Verificou-se que, com exceção dos Pedons 1 e 3, os teores tanto de $\mathrm{K}$ como de Ca foram baixos e uniformes. Devido a esta razão somente os valores médios destes elementos no solo e na fração areia são aqui apresentados (Quadro 2).

O Pedon 1 apresenta uma quantidade apreciável de $\mathrm{K}(0,22 \%)$ mas um baivo teor de cálcio $(0,02 \%)$. O teor tanto de $\mathrm{K}$ como do Ca na fração areia é baixo. Aparentemente o elevado teor relativo de mica e vermiculita deste solo (Demattê, 1975), em torno de 15\%, parece ser a causa do elevado teor de $\mathrm{K}$. Existe também indicações que na fração areia deve existir minerais ricos em $\mathrm{K}$ pois o valor de $0,08 \%$ nesta fração ainda é mais elevado do que nos demais solos, com exceção do Pedon 3.

Os teores muito baixos de $\mathrm{K}$ e Ca na areia do Pedon 2 indica que esta fração é deficiente em minerais intemperizáveis e desde que esta fração constitue uma elevada proporção para o solo (acima de $89 \%$ no Ap, Demattê, 1975), ela reflete em todo o solo.

O Pedon 3 é totalmente diferente dos demais solos estudados devido aos elevados valores de $\mathrm{K}$ e da presença de "linha de pedras" entre 96-103 $\mathrm{cm}$. Neste solo o teor de $\mathrm{K}$ é de $0,29 \%$ e $1,23 \%$ acima e abaixo da linha de pedras. Na fração areia tais valores são também elevados 


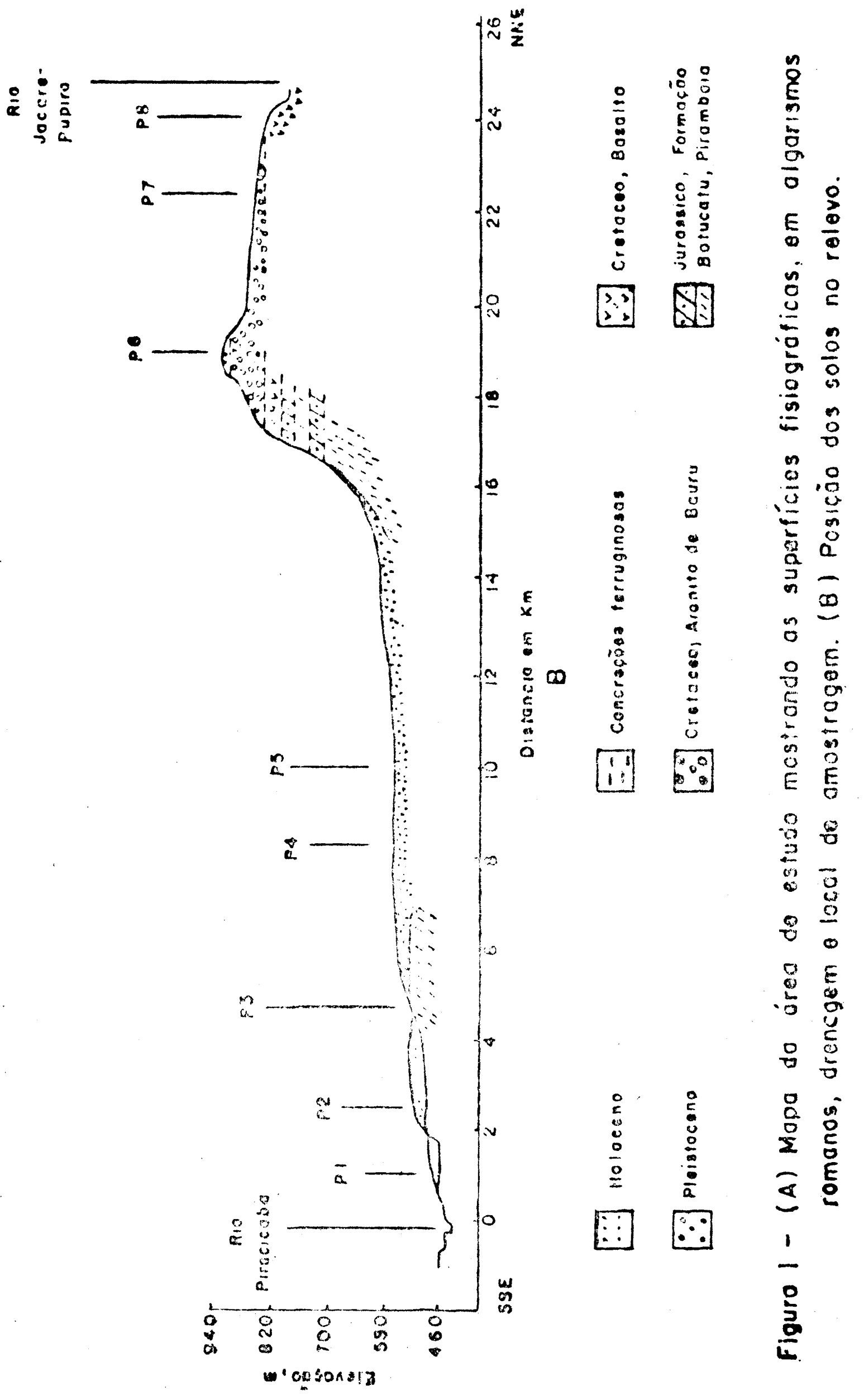


Quadro 2. Teores em porcentagem de cálcio e potássio no solo total $(<2 \mathrm{~mm}$ ) na areia total $(2-0,05 \mathrm{~mm})$ para todos os solos estudados.

\begin{tabular}{|c|c|c|c|c|}
\hline \multirow{2}{*}{ Pedon } & \multicolumn{2}{|c|}{ Solo total } & \multicolumn{2}{|c|}{ Areia total } \\
\hline & $\mathrm{K}^{+}$ & $\mathrm{Ca}^{++}$ & $\mathrm{K}^{+}$ & $\mathrm{Ca}^{++}$ \\
\hline 1 & 0,22 & 0,03 & 0,08 & 0,02 \\
\hline 2 & 0,06 & 0,02 & 0,02 & 0,02 \\
\hline 3 (acima de linha de pedras) & 0,29 & 0,03 & 0,11 & 0,02 \\
\hline 3 (abaixo da linha de pedras) & 1,23 & 0,02 & 0,49 & 0,02 \\
\hline 4 & 0,04 & 0,02 & 0,02 & 0,02 \\
\hline 5 & 0,04 & 0,02 & 0,02 & 0,02 \\
\hline 6 & 0,08 & 0,02 & 0,04 & 0,02 \\
\hline 7 & 0,05 & 0,02 & 0,02 & 0,02 \\
\hline 8 & 0,06 & 0,02 & 0,05 & 0,04 \\
\hline
\end{tabular}

indicando a presença de minerais intemperizáveis tal como a mica, especialmente abaixo da "linha de pedras". O teor relativamente elevado de $\mathrm{K}$ no solo total é atribuído, em parte, devido a fração areia mas também devido a presença de mica e vermiculita na fração argila (em torno de $20 \%$ nos horizontes abaixo a linha de pedras, Demattê, 1975). O teor de Ca no pedon é muito baixo, tanto na fração areia como no solo total. Tal fato sugere que os minerais contendo CA são mais susceptíveis ao intemperismo do que os minerais contendo $\mathrm{K}$.

Pedons 4 e 5 apresentam baixíssimos teores de $\mathrm{K}$ e Ca tanto no solo como na fração areia. Desde que tais solos são arenosos conclue-se que a fração areia é muito pobre em minerais que poderiam ter $\mathrm{K}$ e $\mathrm{Ca}$ em sua composição. Consequentemente é um solo com um baixíssimo potencial de reserva nutricional.

Todos os solos localizados nas superfícies mais elevadas (Pedons 6. 7 e 8) possuem teores de $\mathrm{K}$ e $\mathrm{Ca}$ muito baixos, mas existe algumas diferenças entre tais pedons principalmente no teor de $\mathrm{K}$. Os teores de $K$ da fração areia $(0,04 \%)$ e do solo $(0,08 \%)$ sugere a ocorrência de minerais com $\mathrm{K}$ nas frações areia e argila. O teor mais elevado de $\mathrm{K}$ neste solo $(0,10 \%)$ foi encontrado a $93 \mathrm{~cm}$ de profundidade (dado ñ̃o apresentado). Este aumento em $\mathrm{K}$ com a profundidade pode ser explicado devido a posição que este solo ocupa no relevo. Sua posição é a mais alta (Fig. 1), pertencendo a superfície VI, a mais antiga. Consequentemente a erosão tem removido as porções mais intemperizadas 
expondo as partes menos atacadas pelo intemperismo. Os baixos teores de Ca tanto na areia como no solo total indica que praticamente todo este elemento tem sido perdido por intemperismo.

Os baixos teores de $\mathrm{Ca}$ e $\mathrm{K}$ encontrados no Pedon 7 indicam uma quase inexistência de minerais contendo tais elementos. Semelhantes resultados são encontrados no Pedon 8. Entretanto os teores de $\mathrm{K}$ da fração areia é semelhante aos da fração argila para o Pedon 8. Tal fato indica que a principal fonte fornecedora de $\mathrm{K}$ neste solo é a fração argila.

\section{CONCLUSÕES}

1. Os teores mais elevados de $\mathrm{K}$ encontrados nos Pedons 1 e 3 indicam que os materiais das superfícies I e III são menos intemperizados e portanto de origem mais recente.

2. A fração areia dos solos estudados, com exceção do Pedon •, possue baixíssimos valores de $\mathrm{K}$ e $\mathrm{Ca}$, consequentemente de minera1s contendo tais elementos.

3. Com exceção do Pedon 3 os solos não possuem reserva mineral na fração areia.

4. De todos os solos estudados os Pedons 6, 7 e 8, localizados nas superfícies mais antigas, são os mais intemperizados.

5. Em poucos casos os horizontes superiores mostraram um ligeiro aumento em Ca. Tal fato foi atribuído a reciclagem deste elemento.

\section{SUMMARY}

\section{USE OF X-RAY FLUORESCENCE IN CALCIUM AND POTASSIUM DETFRMINATION IN SOILS}

$\mathrm{Ca}$ and $\mathrm{K}$ content of sand fraction and whole soil of eight pedons representing soils found on successively higher landscape north of Piracicaba River in São Pedro region were studied. Some of the conclutions that can be drawn from the $\mathrm{K}$ and $\mathrm{Ca}$ data are:

- It Kas found that with the exception of Pedon 1 and 3 the contents of both $K$ and $\mathrm{Ca}$ are very low. The higher contents of $\mathrm{K}$ found in these soils indicate that materials on surface $I$ and III hawe undesgone less weathering and can be considered to have been exposed to weathered more recently. 
- The sand fraction of all soils, with the exception of Pedon 3, has a very low content of both $\mathrm{Ca}$ and $\mathrm{K}$ and hence has low content, if any, of weatherable minerals.

- Pedons 6, 7 and 8 although they contain appreciabele clay, have wery low content of $\mathrm{K}$ and $\mathrm{Ca}$ in the soil.

\section{LITERATURA CITADA}

ALEXANDER, J.D., BEAVERS, A.H., and JOHNSON, P.R. - Zirconium content of coarse silt in loess and till of Wisconsin age in Northern Illinois. Soil Sci., Soc. Amer. Proc. 26: 189-191. 1962.

BEAVERS, A.H. - Use of X-ray spectrography analysis for the study of soil genesis. Trans. Seventh Inter. Cong. Soil Sci. Madison. 2: 1-9. 1960.

CHAPMAN, S.L., and HORN, M.E. - Parent material uniformity and origin of solty soils in northwest Arkansas based on $\mathrm{Zr}$, Ti contents. Soil Sci. Soc. Amer. Proc. 32: 265-271. 1968.

DEMATTE, J.L.I. - Characteristics and Classification of a Toposequence of Soils near Piracicaba, Brasil. PhD Dissertation. The Ohio State University. 1975.

DRESS, R. - Elemental variability within a sampling unit. M.S. Thesis. Agronomy Department. Ohio State University. 1970.

FOSS, J.E., and RUST, R.H. - Soil genesis study of a lithologia discontinuity in glacial drift in Western Wisconsin. Soil Sci. Soc. Amer. Proc. 32: 393-398. 1978.

HANDY, R.L., and ROSAUER, E.A. - X-ray fluorescence analysis of total iron and manganese in soil. Iowa Acad. of Soil Proc. 66: 237-245.

KHAN, D.H. - Studies of transformation of chemical constituints in some Red-Brown Soils, Terra Rossas and Rendzinas, using zirconium as a weathering indez. Soil Sci. 88: 196-200. 1959.

KHANGAROT, A.S. - Relative intensity of soil of soil weathering of Wisconsin and Illinoi an - age Terraces near Newark, Ohio. Ph.D. Dissertation, Ohio State University .

RUTLEDGE, E.M. - Loess in Ohio: Composition in relation to several local rivers. $\mathrm{Ph} . \mathrm{D}$. Dissertation. The Ohio State University. 1969.

SMECK, N.E., WILDING, L.P. and HOLOWAYCHUK, N. - Genesis of argillic horizons in Celina and Morley soils of western Ohio. Soil Sci. Soc. Amer. Proc. 32: $550-556.1968$. 
